\title{
Chemistry and Dynamics of Ge in Kesterite: Toward Band-Gap- Graded Absorbers
}

José Márquez, ${ }^{*}{ }^{\dagger} \odot$ Helena Stange, ${ }^{\dagger}$ Charles J. Hages, ${ }^{\dagger}$ Norbert Schaefer, ${ }^{\dagger}$ Sergiu Levcenko, ${ }^{\dagger}$ Sergio Giraldo, ${ }^{\S \odot}$ Edgardo Saucedo, ${ }^{\S}$ Klaus Schwarzburg, ${ }^{\dagger}$ Daniel Abou-Ras, ${ }^{\dagger}$ Alex Redinger, ${ }^{\dagger}, \|$ Manuela Klaus, ${ }^{\dagger}$ Christoph Genzel, ${ }^{\dagger}$ Thomas Unold, ${ }^{\dagger}$ and Roland Mainz ${ }^{\dagger}$

${ }^{\dagger}$ Helmholtz-Zentrum Berlin for Materials and Energy, Hahn-Meitner-Platz 1, 14109 Berlin, Germany

${ }^{\ddagger}$ Institut für Werkstoffwissenschaften, Technische Universität Berlin, Ernst-Reuter Platz 1, 10587 Berlin, Germany

${ }^{\S}$ Catalonia Institute for Energy Research (IREC), C. Jardins de les Dones de Negre 1, Sant Adrià del Besòs, 08930 Barcelona, Spain

"Scanning Probe Microscopy Laboratory, Physics and Materials Science Research Unit, University of Luxembourg, 162a avenue de la Faïencerie, L-1511 Luxembourg

\section{Supporting Information}

\begin{abstract}
The selenization of metallic $\mathrm{Cu}-\mathrm{Zn}-\mathrm{Sn}-\mathrm{Ge}$ precursors is a promising route for the fabrication of low-cost and efficient kesterite thin-film solar cells. Nowadays, efficiencies of kesterite solar cells are still below $13 \%$. For $\mathrm{Cu}(\mathrm{In}, \mathrm{Ga}) \mathrm{Se}_{2}$ solar cells, the formation of compositional gradients along the depth of the absorber layer has been demonstrated to be a key requirement for producing thin-film solar cells with conversion efficiencies above the $22 \%$ level. No clear understanding has been reached so far about how to produce these gradients in an efficient manner for kesterite compounds, but among the possible candidates, Ge arises as one of the most promising ones. In the present work, we evaluate the potential of incorporating $\mathrm{Ge}$ in $\mathrm{Cu}_{2} \mathrm{ZnSnSe}_{4}$ to produce compositional gradients in kesterites. Synchrotron-based in situ energydispersive X-ray diffraction and X-ray fluorescence have been used to study the selenization of $\mathrm{Cu}-\mathrm{Zn}-\mathrm{Sn}-\mathrm{Ge}$ metallic precursors. We propose a reaction mechanism for the incorporation of $\mathrm{Ge}$ atoms into the kesterite lattice after the formation of $\mathrm{Cu}_{2} \mathrm{ZnSnSe}{ }_{4}$. Electron microscopy reveals that the annealing process leads to $\mathrm{Cu}_{2} \mathrm{Zn}(\mathrm{Sn}, \mathrm{Ge}) \mathrm{Se}_{4}$ absorber layers with an increase of $\mathrm{Ge}$ content toward the back contact with independence of the original location of $\mathrm{Ge}$ in the precursor layer. The effect of the Ge gradient on the optoelectronic properties of the absorber layer has been evaluated with room-temperature cathodoluminescence. The implications of the results for the development of kesterite solar cells are discussed, with the aim of encouraging new synthesis routes for compositionally graded absorbers.
\end{abstract}

\section{INTRODUCTION}

Recent developments in the field of thin-film solar cells based on $\mathrm{Cu}(\mathrm{In}, \mathrm{Ga}) \mathrm{Se}_{2}$ (CIGSe) have resulted in large progress in terms of record performances in the lab with efficiencies exceeding $22 \%{ }^{1-3}$ These efficiency levels have been achieved through producing absorber layers with a variable band gap along its depth and with surface treatments. ${ }^{3}$ These band-gap variations in CIGSe solar cells are achieved with synthesis processes designed to result in compositionally graded absorber layers. ${ }^{1,2}$ The great advantage of compositionally graded absorber layers is that, with composition, the position of the valence band and the conduction band can be modified along the thin film to minimize recombination losses and improve the performance of the solar cells. ${ }^{1,4}$ An increased concentration of Ga in CIGSe toward the back contact helps in driving the photogenerated minority carriers to the heterojunction and reduces their recombination at the back contact. In CIGSe, this type of gradient leads to substantial improvements of open-circuit voltage $\left(V_{\text {oc }}\right)$ and charge carrier collection. ${ }^{4,5}$

Current efficiency levels of kesterites are below $13 \%,{ }^{6}$ because of short minority carrier lifetimes in the sub-nano-second regime. ${ }^{7}$ Kesterite compounds like $\mathrm{Cu}_{2} \mathrm{Zn}(\mathrm{Sn}, \mathrm{Ge})(\mathrm{S}, \mathrm{Se})_{4}$ as absorber for thin-film solar cells have the potential to contribute to the increase of solar energy in large volumes using earthabundant elements such as $\mathrm{Sn}$ and $\mathrm{Zn}$. The capability of these compounds to host various elements in the same atomic position, such as $\mathrm{Sn}$ and $\mathrm{Ge}$ in $\mathrm{Cu}_{2} \mathrm{Zn}(\mathrm{Sn}, \mathrm{Ge}) \mathrm{Se}_{4}$ (CZTGeSe), allows tuning of the band gap of the compound by varying the composition similar to CIGSe. The band gap of these compounds is found to increase from $\sim 1.0 \mathrm{eV}$ for $\mathrm{Cu}_{2} \mathrm{ZnSnSe}_{4}$ $(\mathrm{CZTSe})^{8}$ to $\sim 1.4 \mathrm{eV}$ for $\mathrm{Cu}_{2} \mathrm{ZnGeSe}_{4}{ }^{9,10}$ and both crystallize in

Received: August 12, 2017

Revised: October 17, 2017

Published: October 17, 2017 
the kesterite-type structure. ${ }^{11,12}$ With synthesis of the solid solution CZTGeSe and tuning of the $[\mathrm{Sn}] /[\mathrm{Ge}]$ ratio, the bandgap energy of the compounds can be varied almost linearly with composition. ${ }^{10,13}$ This band-gap variation is expected to occur mainly by changes in the energy position of the conduction band minimum (CBM). This is because the CBM is mainly derived from the Ge or Sn $4 \mathrm{~s}$ and the Se p states, and the valence band maximum (VBM) is derived from the hybridization of $\mathrm{Cu} 3 \mathrm{~d}$ and Se $p$ states; ${ }^{9}$ i.e., the CBM position can be potentially tuned within the absorber layer by controlling the depth distribution of Sn and Ge. ${ }^{14}$

In kesterites, the formation and control of band-gap gradients by varying the anion composition ( $\mathrm{S}$ and $\mathrm{Se}$ ) has been identified as a challenging task. ${ }^{15}$ Sulfur enrichment at the surface has been accomplished in a two-stage process resulting in large gains of open-circuit voltage $V_{\text {oc }}$ and efficiencies of more than $12 \%$ owing to a band-gap increase near the heterojunction interface. ${ }^{16,17}$

Several groups have reported substantial improvements in the performance of CZTSe solar cells by the incorporation of Ge. These improvements are mainly driven by $(1)$ increased $V_{\text {oc }}$ and fill factor (FF) values, ${ }^{13,18-24}$ (2) improved charged carrier collection, ${ }^{13,18,19}$ and (3) longer decay times in time-resolved photoluminescence (TRPL) measurements. ${ }^{13,23}$ However, the reasons for these improvements have rarely been attributed to a compositional gradient along the film. Instead, these improvements have been associated with other effects such as (a) reduction of the concentration of deep defects, ${ }^{18}$ (b) improved crystallinity, $^{18,19}$ (c) reduction of band tailing, ${ }^{23}$ and (d) better control of elemental losses. ${ }^{13}$

To be able to optimize synthesis routes for the fabrication of graded CZT $(\mathrm{Ge}) \mathrm{Se}$ absorber layers such as what is found in highefficiency CIGSe solar cells, ${ }^{1}$ it is crucial to understand the chemistry and dynamics of $\mathrm{Ge}$ in kesterite compounds. Initial studies in the formation of Ge-Sn-graded CZTGS absorbers from nanocrystal precursors have been reported by Kim et al. ${ }^{25}$ Depletion of Ge toward the surface ${ }^{25}$ or Ge accumulation toward the back contact has been observed. ${ }^{13}$ However, the mechanism of formation of the $\mathrm{Ge}-\mathrm{Sn}$ gradient during annealing remains unclear. In this paper, the mechanism behind the synthesis of $\mathrm{Sn}-\mathrm{Ge}$ compositionally graded kesterite absorbers is studied by in situ energy-dispersive X-ray diffraction and X-ray fluorescence (EDXRD/XRF) which allows time resolutions of one spectrum every three seconds. The results presented here provide insights in the chemistry of the Ge incorporation in CZTSe and the gradient formation.

\section{EXPERIMENTAL SECTION}

$\mathrm{Cu} / \mathrm{Sn} / \mathrm{Cu} / \mathrm{Zn}$ metallic stacks were sputtered on Mo-coated soda lime glass substrates with compositional ratios of $[\mathrm{Cu}] /([\mathrm{Zn}]+[\mathrm{Sn}])=0.75$ and $[\mathrm{Zn}] /[\mathrm{Sn}]=1.20$ as determined with calibrated $\mathrm{X}$-ray fluorescence (XRF, Fischerscope XVD). ${ }^{18}$ An additional set of precursors were prepared with a $50 \mathrm{~nm}$ thick Ge layer thermally evaporated on top of the $\mathrm{Cu} / \mathrm{Sn} / \mathrm{Cu} / \mathrm{Zn}$ metallic stacks. ${ }^{19}$ The evaporation was performed in an Oerlikon Univex 250. For an understanding of the growth mechanisms of kesterite compounds in the presence of $\mathrm{Ge}$, different selenization processes were performed using a $\mathrm{Cu} / \mathrm{Sn} / \mathrm{Cu} / \mathrm{Zn}$ stack with and without a $50 \mathrm{~nm}$ Ge layer on top of the precursor.

The precursors were annealed in selenium vapor inside a cylindrical graphite reaction box (reactor) placed inside a vacuum chamber. ${ }^{26}$ For the reactive annealing, $200 \mathrm{mg}$ of Se pellets was placed in a ceramic crucible next to the sample. The reactor was sealed with a motorized valve at a pressure of $\sim 10^{-4}$ mbar and heated by halogen lamps. The temperature of the processes was controlled and recorded with a thermocouple located $5 \mathrm{~mm}$ above the sample. The heating rate was set to $20 \mathrm{~K} / \mathrm{min}$ which is similar to rates found for conventional tube furnaces. A two-step selenization process similar to the one used for fabricating solar cells with efficiencies over $10 \%$ was studied, with a first dwelling step at $400{ }^{\circ} \mathrm{C}$ for $30 \mathrm{~min}$ and a second one at $500{ }^{\circ} \mathrm{C}$ for 15 min. ${ }^{19}$ The temperature profile for this process is shown in Figure 1a.

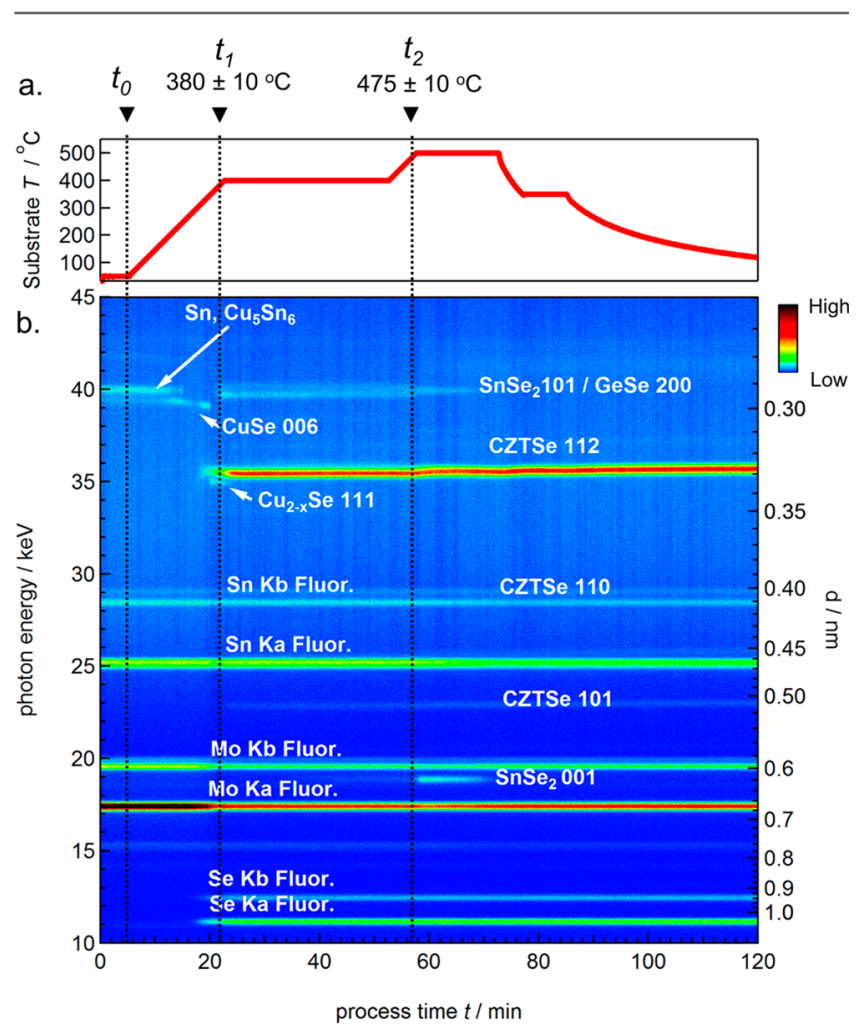

Figure 1. (a) Substrate temperature during the process. (b) Colorcoded representation of the EDXRD/XRF intensities as a function of photon energy and process time recorded during the selenization of a metallic $\mathrm{Cu} / \mathrm{Sn} / \mathrm{Cu} / \mathrm{Zn} / \mathrm{Ge}$ stack. The right axis shows the lattice plane distance $d$ calculated from the photon energy values using the Bragg equation. The Mo, Sn, and Se fluorescence signals and the reflections of the following phases are indicated in the plot: CuSe (PDF 86-1239), $\mathrm{Cu}_{2-x} \mathrm{Se}$ (PDF 073-2712), CZTSe (PDF 070-8930), $\mathrm{SnSe}_{2}$ (PDF 01089-2939), Sn (PDF 01-086-2266), $\mathrm{Cu}_{5} \mathrm{Sn}_{6}$ (PDF 01-072-8761), and GeSe (PDF 01-071-4730).

For evaluation of shorter selenization times, an additional $\mathrm{Cu} / \mathrm{Sn} / \mathrm{Cu} /$ $\mathrm{Zn} / \mathrm{Ge}$ sample was studied with a single heating $\mathrm{ramp}(20 \mathrm{~K} / \mathrm{min})$ up to $500{ }^{\circ} \mathrm{C}$ and a dwell time of $10 \mathrm{~min}$. During the cool-down step, the reactor valve was opened for $5 \mathrm{~min}$ at $350{ }^{\circ} \mathrm{C}$ to remove potential residual vapor phases.

The annealing chamber ${ }^{26}$ was coupled to the polychromatic EDDI beamline $^{27}$ of the BESSY II synchrotron facility. During the annealing, diffraction and fluorescence signals were recorded in an energydispersive high-purity Ge detector under a scattering angle of $2 \theta=3.041$ ${ }^{\circ} \pm 0.002$. The relationship between the lattice plane spacing $d_{h k l}$ of a crystalline phase and the photon energy $E_{h k l}$ of the corresponding diffraction line follows the energy-dispersive Bragg law $E_{h k l}=h c /\left(2 d_{h k l}\right.$ $\sin \theta$ ), where $h$ is Planck's constant and $c$ the speed of light.

Elemental distributions were measured by means of energy-dispersive X-ray spectroscopy (EDX) conducted in a Zeiss Ultraplus scanning electron microscope equipped with an Oxford Instruments XMax 80 $\mathrm{mm}^{2}$ silicon drift detector on polished cross-sectional samples. For EDX elemental-distribution maps (net counts), $7 \mathrm{kV}$ acceleration voltage and $90 \mathrm{pA}$ probe current were used.

Cathodoluminescence $(\mathrm{CL})$ hyperspectral maps were measured with a Zeiss Merlin SEM instrument equipped with a Delmic Sparc CL detection system. Point exposure time on the InGaAs array detector was $3 \mathrm{~s}$ for a $10 \mathrm{kV}$ acceleration voltage and a $10 \mathrm{nA}$ beam current. 


\section{With $50 \mathrm{~nm} \mathrm{Ge}$}

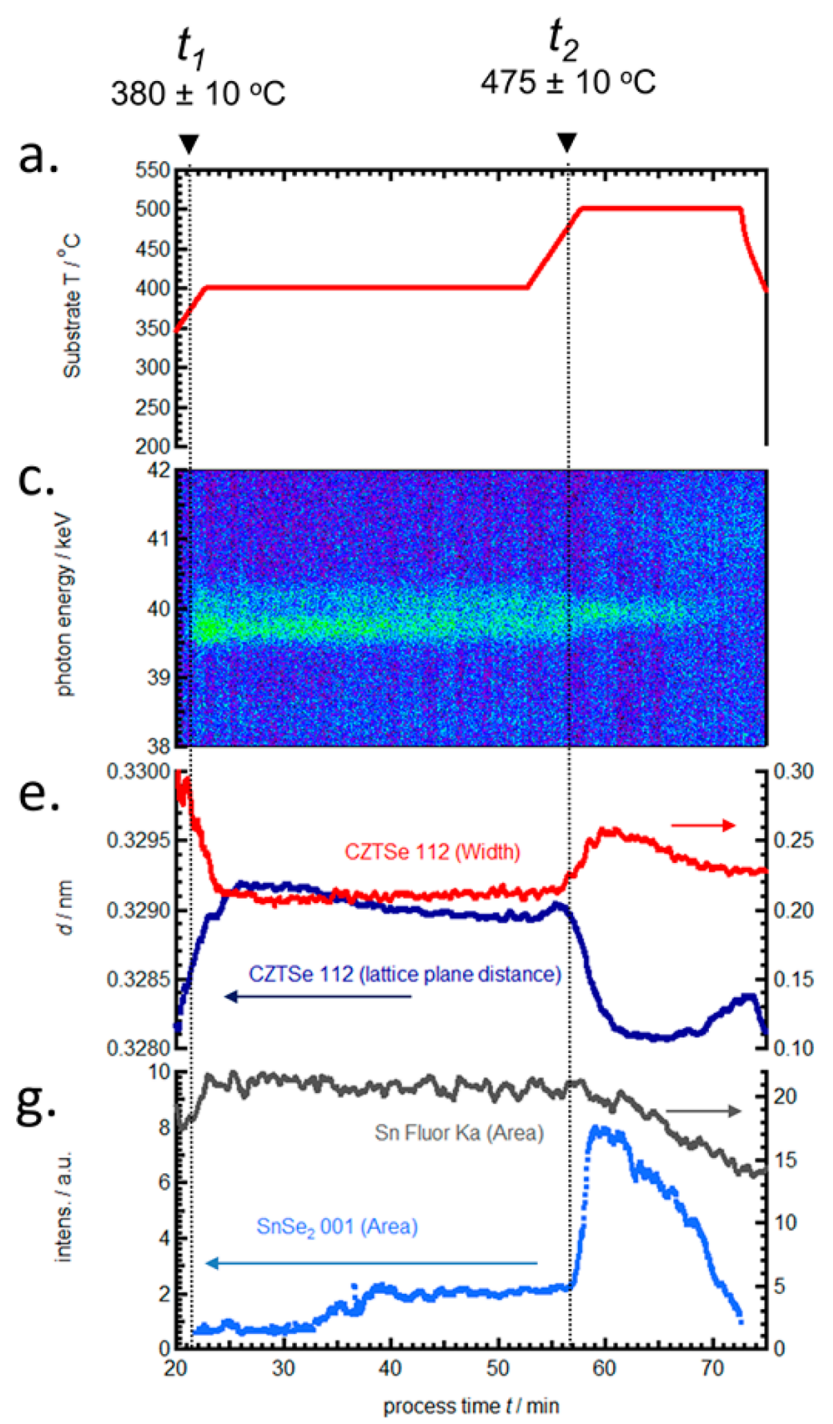

Without Ge

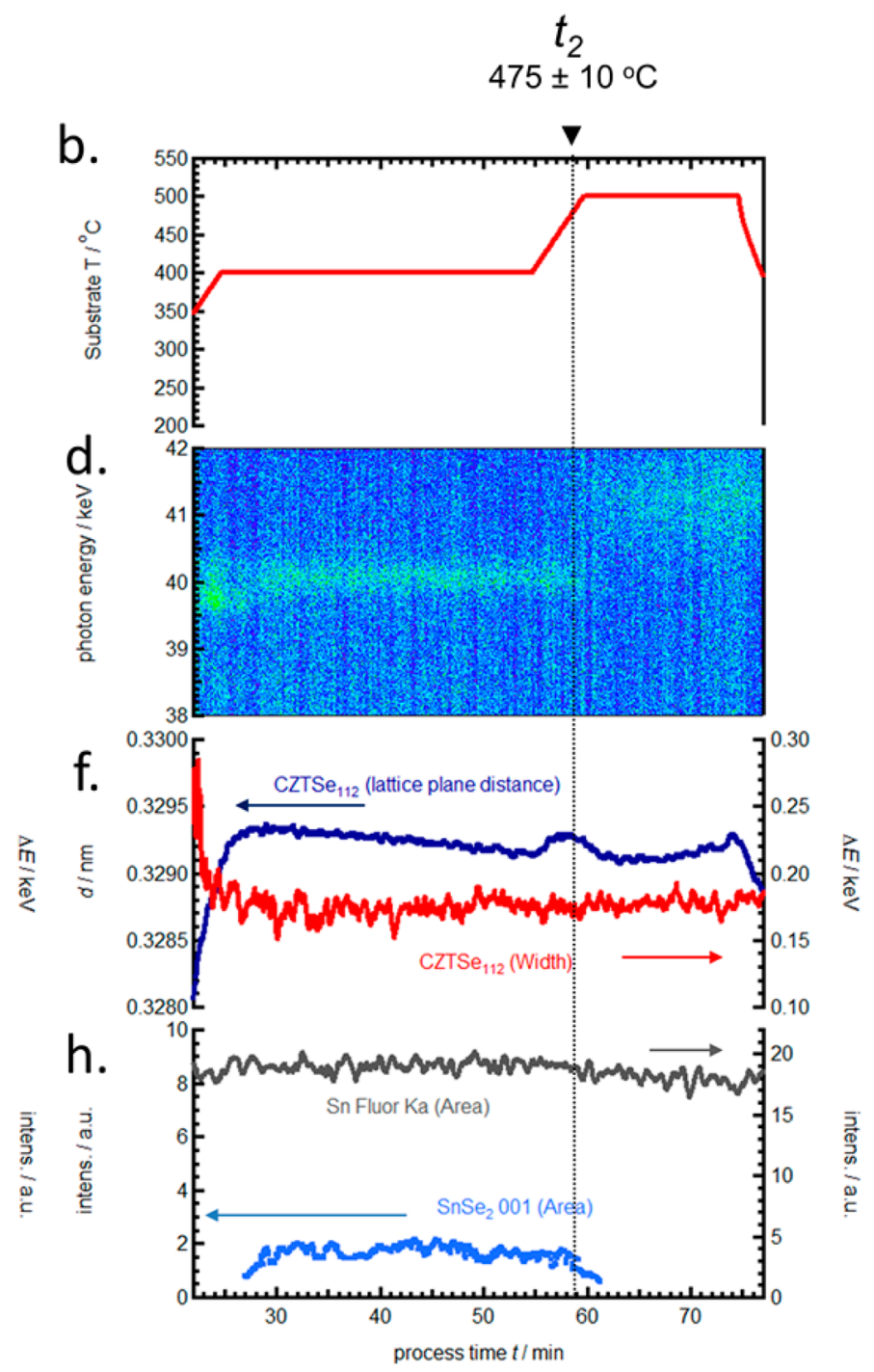

Figure 2. Plots related to $(a, c, e, g)$ the selenization process of the $\mathrm{Cu} / \mathrm{Sn} / \mathrm{Cu} / \mathrm{Zn} / \mathrm{Ge}$ stack and $(b, d, f$ and $h)$ the selenization of the $\mathrm{Cu} / \mathrm{Sn} / \mathrm{Cu} / \mathrm{Zn}$ stack. All plots are a function of the process time ( $x$-axis). (a, b) Temperatures measured for the selenization processes. (c, d) Magnification of the colorcoded EDXRD signals with photon energies from 38 to $42 \mathrm{keV}$. (e, f) Calculated lattice plane distance (dark blue: left $y$-axis) and the width (red: right $y$ axis) of the CZT $(\mathrm{Ge}) \mathrm{Se} 112$ diffraction signal. $(\mathrm{g}, \mathrm{h})$ Values of the area of the $001 \mathrm{SnSe}_{2}$ diffraction signal (light blue: left $y$-axis) and the Sn K $\alpha$ fluorescence (gray: right $y$-axis).

\section{RESULTS AND DISCUSSION}

3.1. Real-Time Phase Analysis. 3.1.1. Selenization of the Metallic Precursor and Formation of the Kesterite Phase. EDXRD/XRF data recorded during the two-step selenization of the sample with a $50 \mathrm{~nm}$ Ge capping layer are shown in Figure 1 . The plot shows color-coded diffraction and fluorescence signals as a function of photon energy, lattice plane distance $d$, and process time $t$. (A similar plot for the sample without Ge can be found in the Supporting Information, Figure S1.)

At the beginning of the process $\left(t_{0}\right.$, Figure 1$)$, a diffraction signal of the metal precursor (overlapping peaks of $\mathrm{Sn}$ and $\mathrm{Cu}_{5} \mathrm{Sn}_{6}$ ) can be observed at around $40 \mathrm{keV}$, along with the fluorescence signals of Se, Mo, and Sn. The diffraction signal of the metal precursor starts to vanish at temperatures around the melting point of $S n \sim 231{ }^{\circ} \mathrm{C}(15 \mathrm{~min}$ process time $){ }^{28}$ Shortly after this, the fluorescence signals of Se start to appear, indicating the beginning of the first reactions with Se in the film. As the Se fluorescence signals increase in intensity, the Mo signals decrease. This can be explained by the attenuation of these signals due to the Se incorporation.

The first crystalline binary phase observed is CuSe (PDF 86$1239)^{29}$ which can be tracked by the 006 reflection appearing at around $39 \mathrm{keV}$. This signal disappears at $\sim 340{ }^{\circ} \mathrm{C}(20 \mathrm{~min}$ process time). At this time, a reflection corresponding to the $\mathrm{Cu}_{2-x} \mathrm{Se}$ (PDF 073-2712) phase arises at photon energies around $35 \mathrm{keV}$. Simultaneously, a diffraction signal near the expected position of CZTSe 112 at $35.5 \mathrm{keV}$ appears, indicating the initial formation of the $\mathrm{CZT}(\mathrm{Ge})$ Se phase. While this reflection cannot be unambiguously attributed to kesterite because of similar peak positions of $\mathrm{CT}(\mathrm{Ge}) \mathrm{Se}$ and $\mathrm{ZnSe}$, the simultaneous rising of the peak near the position of CZT $(\mathrm{Ge}) \mathrm{Se} 101(23 \mathrm{keV})$ confirms the formation of the kesterite phase. ${ }^{30}$

The early formation of $\mathrm{Cu}-\mathrm{Se}$ binaries has been proposed to be promoted by a fast diffusion of $\mathrm{Cu}$ toward the surface of the film compared to the other elements. ${ }^{30}$ This mechanism has also 
been proposed for CIGSe where $\mathrm{Cu}$ has a higher diffusivity than In and $\mathrm{Ga}$ and reaches the surface of the film where it starts reacting with the Se vapor. ${ }^{31}$

Slightly after the appearance of the diffraction signal of $\mathrm{CZT}(\mathrm{Ge})$ Se 112, a broad double peak feature emerges at $39 \mathrm{keV}$ at around $\sim 380{ }^{\circ} \mathrm{C}\left(t_{1}=22 \mathrm{~min}\right.$; Figures 1 and 2$)$. These two peaks can be attributed to the reflections of GeSe 200 (PDF 01071-4730) and $\mathrm{SnSe}_{2} 101$ (PDF 01-089-2939) and are present during the entire dwell time at $400{ }^{\circ} \mathrm{C}$. Figure $2 \mathrm{c}$,d shows a magnification of the double peak feature for the sample with 50 $\mathrm{nm}$ of $\mathrm{Ge}$ added and without $\mathrm{Ge}$ for comparison. For the sample without $\mathrm{Ge}$, the double shoulder peak cannot be seen, and just a low-intensity peak at around $40 \mathrm{keV}$ is present (Figure $2 \mathrm{~d}$ ), confirming that for the sample with Ge the low-energy side of the double peak arose from a Ge-containing phase (Figure 2c). Without loss of $\mathrm{Sn}$, the presence of $\mathrm{Sn}-\mathrm{Se}$ binary phases is expected considering that the precursors used for this study have Cu-poor composition. ${ }^{32}$

3.1.2. Ge Incorporation and $\mathrm{SnSe}_{2}$ Segregation. At $\sim 475^{\circ} \mathrm{C}$ in the second ramping step, the signal of the 200 reflection of GeSe vanishes ( $t_{2}=57 \mathrm{~min}$; see Figures 1 and 2 ). Simultaneously, the intensity of a previously faint signal at $19 \mathrm{keV}$ attributed to $\mathrm{SnSe}_{2} 001$ increases substantially (as shown in Figure 1), indicating the segregation of this phase. The evolution of the integral intensity of this reflection is plotted in Figure $2 \mathrm{~g}$. In contrast, an increase in intensity of this signal is not observed for the selenization of the $\mathrm{Cu} / \mathrm{Sn} / \mathrm{Cu} / \mathrm{Zn}$ sample without $\mathrm{Ge}$ (Figure 2h). Interestingly, for the sample with $\mathrm{Ge}$, the $\mathrm{SnSe}_{2} 101$ reflection $(\sim 40 \mathrm{keV}$, Figure $2 \mathrm{c})$ does not show such an increase in intensity at $t_{2}=57 \mathrm{~min}$ as observed for the $001 \mathrm{SnSe}_{2}$ signal, suggesting that the segregated phase exhibits strong preferential orientation. Figure $2 \mathrm{~g}$, h also shows the evolution of the $\mathrm{Sn} \mathrm{K} \alpha$ fluorescence signal. For the sample with $\mathrm{Ge}$, a clear decrease in the $\mathrm{Sn} \mathrm{K} \alpha$ intensity can be seen as the $001 \mathrm{SnSe}_{2}$ signal decreases during the dwell time at $500{ }^{\circ} \mathrm{C}$. The parallel decline indicates that the $\mathrm{Sn}$ loss occurring in this sample mainly arises from the $\mathrm{SnSe}_{2}$ phase. Sn loss is a mechanism which has been studied in kesterites, and has been associated with processes with longer dwelling times and where the Se partial pressure was low. ${ }^{33-36}$ The poor capability of the annealing reactors to maintain high $S$ and Se partial pressure with time due to leakage or vapor absorption in the reactor walls has also been associated with $\mathrm{Sn}$ loss. ${ }^{37}$ The evaporation of $\mathrm{SnSe}_{2}$ occurs incongruently as represented by eqs 1 and 2. ${ }^{38}$ Under high Se partial pressure, $\mathrm{SnSe}_{2}$ would be stabilized as eq 1 would proceed toward the lefthand side. The decrease of the intensity of the $\mathrm{SnSe}_{2}$ reflection indicates a decrease of the Se partial pressure in the system, similarly observed for $\mathrm{SnS}_{2}$ by in situ Raman spectroscopy measurements. $^{37}$

$$
\begin{aligned}
& \operatorname{SnSe}_{2}(\mathrm{~s}) \leftrightarrow \operatorname{SnSe}(\mathrm{s})+\frac{1}{x} \mathrm{Se}_{x}(\mathrm{~g}) \\
& \operatorname{SnSe}(\mathrm{s}) \leftrightarrow \operatorname{SnSe}(\mathrm{g})
\end{aligned}
$$

For a study of the incorporation of Ge into the kesterite phase, the calculated peak width and the lattice plane distances of the 112 reflection of the $\mathrm{CZT}(\mathrm{Ge})$ Se phases of the samples with and without Ge are shown in Figure 2e,f, respectively. During the 400 ${ }^{\circ} \mathrm{C}$ step of the annealing process, the $d$ values of $\mathrm{CZT}(\mathrm{Ge}) \mathrm{Se} 112$ for both samples are very similar, with slightly smaller values for the Ge-containing sample (Figure 2e), suggesting that the amount of $\mathrm{Ge}$ incorporated into the tetragonal $\mathrm{CZT}(\mathrm{Ge}) \mathrm{Se}$ structure is rather small at this stage. However, during the transition at $t_{2}=57 \mathrm{~min}$ where the GeSe reflection vanishes and $\mathrm{SnSe}_{2}$ segregates, a steep decrease of $d$ for the sample with $50 \mathrm{~nm}$ of Ge occurs (Figure 2e). This shift is not observed in the sample without $\mathrm{Ge}$, implying that the decrease is due to the incorporation of $\mathrm{Ge}$ into the $\mathrm{CZT}(\mathrm{Ge})$ Se lattice.

$\mathrm{Ge}$ atoms, which are smaller than $\mathrm{Sn}$, occupy $\mathrm{Sn}$ positions in the kesterite-type structure, inducing a decrease of the lattice plane distance $d .^{10}$ The detection of the $\mathrm{SnSe}_{2} 101$ signal prior to the incorporation of $\mathrm{Ge}$ at $t_{2}=57 \mathrm{~min}$ suggests that the CZTSe lattice is saturated with $\mathrm{Sn}$. For the incorporation of $\mathrm{Ge}$ atoms into the CZTSe lattice, $\mathrm{Sn}$ atoms would need to leave the structure. We propose that the replacement of $\mathrm{Sn}$ by $\mathrm{Ge}$ in the kesterite structure leads to the further segregation of $\mathrm{SnSe}_{2}$ observed by the increased intensity of the $\mathrm{SnSe}_{2} 001$ signal, as discussed in Section 3.3.

Broadening of a diffraction peak can arise from different sources such as low values of the domain size, increase of microstrain, ${ }^{39,40}$ or compositional gradients. ${ }^{41}$ At the point where the $\operatorname{CZT}(\mathrm{Ge}) \mathrm{Se} 112$ signal shifts to lower $d$ values, indicating incorporation of $\mathrm{Ge}\left(t_{2}=57 \mathrm{~min}\right.$; Figure 2e), the width of the 112 peak clearly increases. Figure 3 shows the diffraction

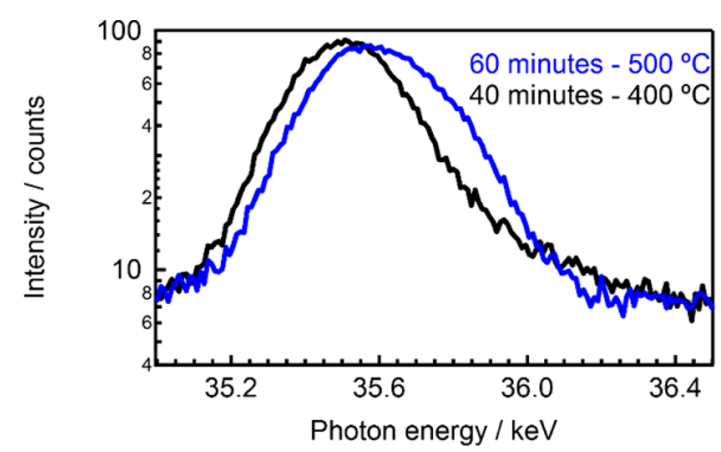

Figure 3. $\mathrm{CZT}(\mathrm{Ge}) \mathrm{Se}$ phase 112 reflection of the $\mathrm{Cu} / \mathrm{Sn} / \mathrm{Cu} / \mathrm{Zn} / \mathrm{Ge}$ stack at $400{ }^{\circ} \mathrm{C}, 40 \mathrm{~min}$ (black); and $500{ }^{\circ} \mathrm{C}, 60 \mathrm{~min}$ (blue).

signal of the 112 of the $\mathrm{CZT}(\mathrm{Ge})$ Se phase before $\left(400{ }^{\circ} \mathrm{C}, 40\right.$ $\mathrm{min})$ and after $\left(500{ }^{\circ} \mathrm{C}, 60 \mathrm{~min}\right)$ the $\mathrm{Ge}$ incorporation. The widening of the peak is asymmetric and more pronounced at the high-energy side. This asymmetric broadening can be explained by the formation of domains which have higher Ge concentration and therefore lower $d$ values than the main part of the film. In Figure 2e it can be seen that, after the Ge incorporation, detected by the shift of the 112 peak to lower $d$ values, the broadening of the peak achieves its maximum, and then, it decreases progressively during the $500{ }^{\circ} \mathrm{C}$ dwell time. This decrease of the width of the peaks is correlated with an increase of $d$. Both variations can be explained by the interdiffusion of $\mathrm{Ge}$ and $\mathrm{Sn}$ which leads to a decrease of the Ge/Sn gradient in the CZTGeSe phase. However, the final width of the peak is still significantly broader $(\sim 0.23 \mathrm{keV})$ and more asymmetric compared to that of the reference sample without $\mathrm{Ge}(\sim 0.18 \mathrm{keV})$. This difference in widths suggests that a compositional gradient still exists at the end of the process, which is analyzed in more detail in the next section.

3.2. Microstructural and Chemical Distribution. For confirmation and improvement of the understanding of the $\mathrm{SnSe}_{2}$ segregation due to Ge incorporation in the CZTS(Ge)Se lattice, a selenization process with a single annealing step at 500 ${ }^{\circ} \mathrm{C}$ for 10 min was performed with a $\mathrm{Cu} / \mathrm{Sn} / \mathrm{Cu} / \mathrm{Zn} / \mathrm{Ge}$ stack. The qualitative phase evolution of this process observed by EDXRD/XRF was similar to the one shown in Figure 1 (see the 
a.

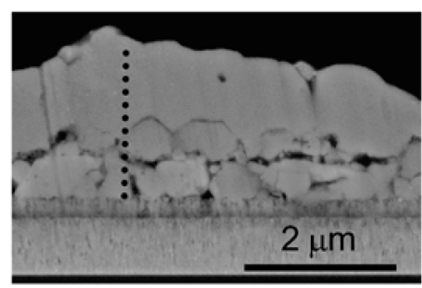

e.

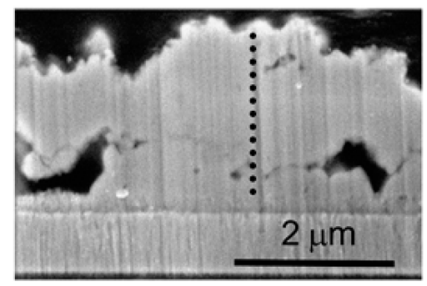

b.

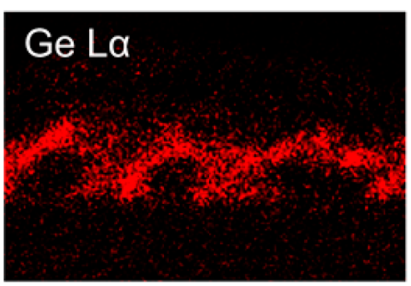

f.

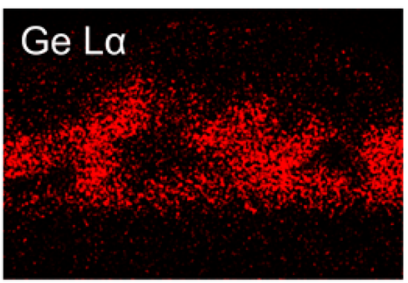

c.

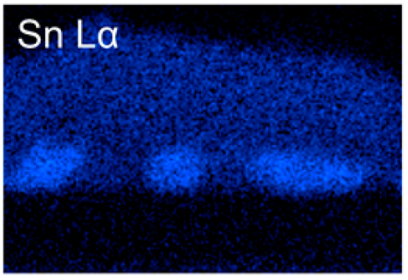

g.

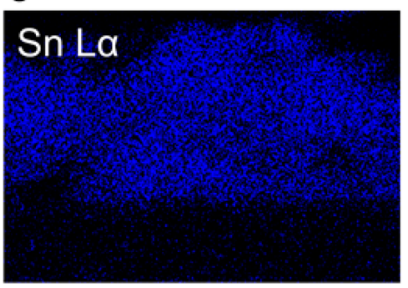

d.
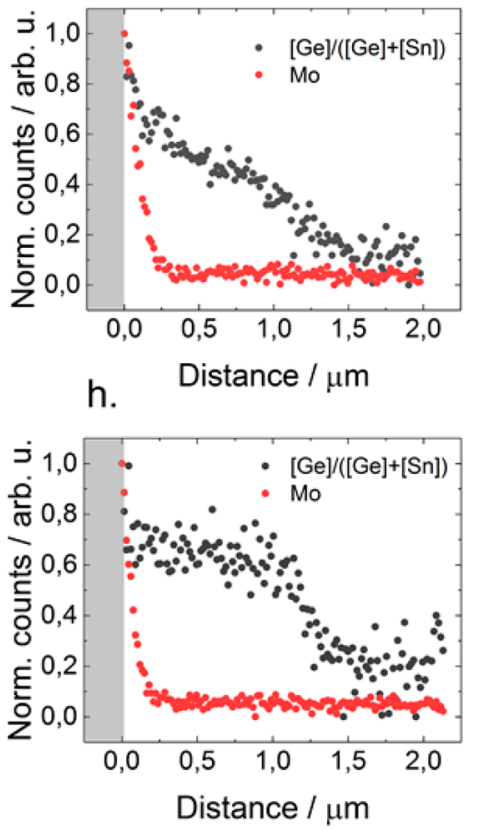

Figure 4. Secondary electron (SE) image and elemental EDX maps and line-scans showing the evolution of the normalized [Ge]/([Ge] $+[\mathrm{Sn}])$ ratio for the $\mathrm{Cu} / \mathrm{Zn} / \mathrm{Sn} / \mathrm{Ge}$ samples selenized with $(\mathrm{a}-\mathrm{d})$ one step, $10 \mathrm{~min}$ at $500{ }^{\circ} \mathrm{C}$; and $(\mathrm{e}-\mathrm{h})$ two steps, $30 \mathrm{~min}$ at $400{ }^{\circ} \mathrm{C}$, and $15 \mathrm{~min}$ at $500{ }^{\circ} \mathrm{C}$. The dotted lines in parts a and e represent the regions where the line-scans were performed. The shadowed areas in parts $\mathrm{d}$ and $\mathrm{h}$ represent the back contact region.

I. Ge incorporation in CZTSe and segregation $\mathrm{SnSe}_{2} \rightarrow \mathrm{T} \sim 475^{\circ} \mathrm{C}$

II. Ge diffusion in CZTSe and $\mathrm{SnSe}_{2}$ loss $\rightarrow f(\mathrm{~T}, \mathrm{t})$

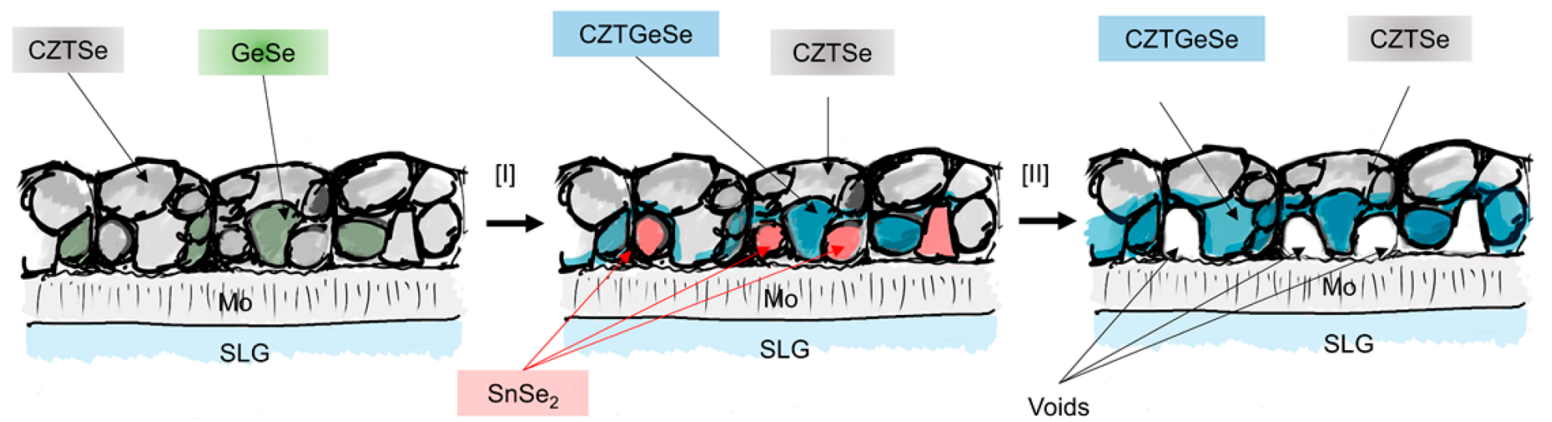

Figure 5. Schematic model showing the incorporation of Ge in CZTSe and the segregation of $\mathrm{SnSe}_{2}$. The model also illustrates a potential route for $\mathrm{SnSe}_{2}$ loss, void formation, and Ge-Sn interdiffusion in the CZT $(\mathrm{Ge}) \mathrm{Se}$ grains. In the sketch, $T$ and $t$ stand for temperature and time, respectively.

Supporting Information, Figure S2). However, the total disappearance of the $\mathrm{SnSe}_{2} 001$ signal could not be observed here, indicating that a Se pressure high enough to prevent the decomposition of $\mathrm{SnSe}_{2}$ to $\mathrm{SnSe}+\mathrm{Se}$ (eq 1) was maintained throughout the process. During the one-step selenization, the total time at temperatures where the $\mathrm{Se}$ is in vapor phase was shorter $\left(10 \mathrm{~min}\right.$ at $\left.500{ }^{\circ} \mathrm{C}\right)$ than in the two step processes presented in Figures 1 and $2\left(30 \mathrm{~min}\right.$ at $400{ }^{\circ} \mathrm{C}$ and $15 \mathrm{~min}$ at 500 $\left.{ }^{\circ} \mathrm{C}\right)$. Therefore, a higher Se pressure at the end of the one-step process is expected.

For evaluation of the chemical distribution of the films after annealing, cross-sectional SEM images and EDX compositional maps were acquired for the samples with $\mathrm{Ge}$ from both annealing processes (two steps, $30 \mathrm{~min}$ at $400{ }^{\circ} \mathrm{C}, 15 \mathrm{~min}$ at $500{ }^{\circ} \mathrm{C}$; and one step, $10 \mathrm{~min}$ at $500^{\circ} \mathrm{C}$ ) which are shown in Figure 4. In the sample annealed with a single step at $500{ }^{\circ} \mathrm{C}$, an increase of $\mathrm{Sn}$ and Se counts in certain regions near the back contacts can be observed. In those locations there are no Ge counts, leading to the conclusion that these are the regions where the accumulation of $\mathrm{SnSe}_{2}$ occurred. In the vicinity of the $\mathrm{SnSe}_{2}$ phase, an increase of counts of $\mathrm{Ge}$ can be seen. This supports our previous assumption that $\mathrm{SnSe}_{2}$ forms during the incorporation of $\mathrm{Ge}$ into the CZTSe lattice by replacement of $\mathrm{Sn}$. The Ge counts are significantly reduced toward the surface of the film as shown in the $[\mathrm{Ge}] /([\mathrm{Ge}]+[\mathrm{Sn}])$ profiles depicted in Figure $4 \mathrm{~d}$.

For the sample annealed with the two-step process, no accumulation of $\mathrm{SnSe}_{2}$ can be observed as expected from the EDXRD data. The distribution of Ge counts is also increased toward the back contact (see Figure $4 \mathrm{~h}$ ), showing that the $\mathrm{Ge} / \mathrm{Sn}$ gradient proposed in the previous section due to the peak widening occurs in the vertical direction (normal to the sample substrate). Also, voids in the interface with the back contact can be seen. The voids can be a consequence of the loss of $\mathrm{SnSe}_{2}$ observed in the in situ EDXRD/XRF data. 

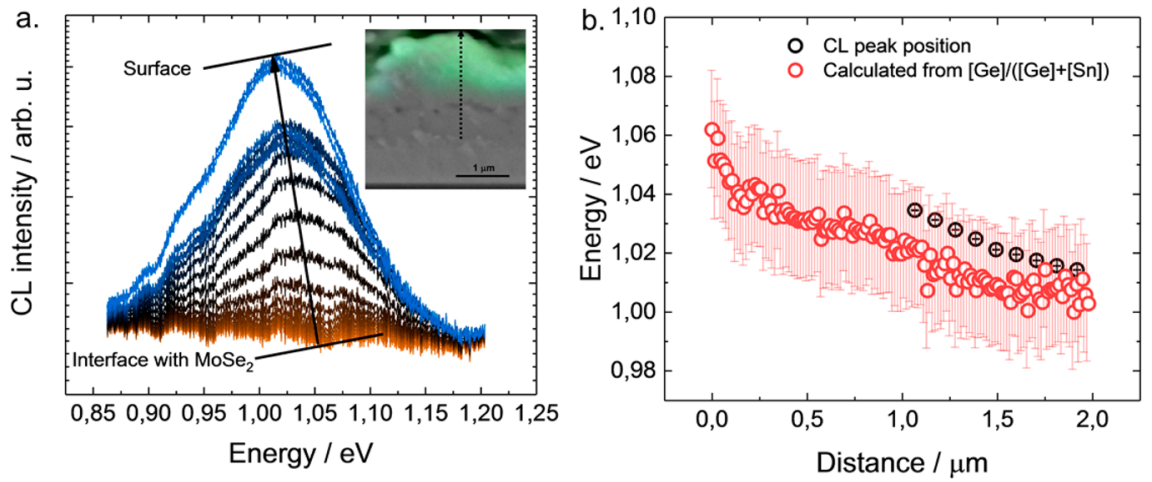

Figure 6. (a) Cathodoluminescence (CL) spectra acquired in a line-scan (dotted arrow in the inset) of the cross-sectional view of the sample selenized with one step, $10 \mathrm{~min}$ at $500^{\circ} \mathrm{C}$. An arrow is depicted for visual guidance of the evolution of the maxima of the CL spectra from the back surface to the top surface of the film. The inset shows an SE image of the cross section of the sample overlaid with the CL signal acquired (in green). (b) CL peak position and $E_{\mathrm{g}}$ calculated from the compositional gradient as a function of the distance from the back contact.

3.3. Growth Mechanism and Ge-Sn Interdiffusion. On the basis of in situ EDXRD/XRF measurements and the results of the morphological and chemical analysis, we propose a mechanism for the Ge incorporation into the $\mathrm{CZT}(\mathrm{Ge})$ Se lattice for the type of samples and processes used in this study. This mechanism is schematically depicted in Figure 5. As previously observed for the selenization of $\mathrm{Cu}-\mathrm{Zn}-\mathrm{Sn}-\mathrm{S}$ nanoparticle precursors, the formation of $\mathrm{Cu}-\mathrm{Se}$ phases precedes the formation of $\mathrm{CZT}(\mathrm{Ge}) \mathrm{Se}^{30,42}$ The formation of CZTSe, with barely any incorporation of $\mathrm{Ge}$ in the lattice; $\mathrm{GeSe}$; and a small amount of $\mathrm{SnSe}_{2}$ occurs at temperatures around $380^{\circ} \mathrm{C}$ (Figure 5a). In the temperature range $380-475^{\circ} \mathrm{C}$, CZTSe coexists with GeSe and some traces of $\mathrm{SnSe}_{2}$. At around $475^{\circ} \mathrm{C}$, GeSe reacts with CZTSe forming CZTGeSe and segregating $\mathrm{SnSe}_{2}$ (Figure $5 \mathrm{~b})$ as described by eq 3 where $x$ is equivalent to the $[\mathrm{Ge}] /([\mathrm{Ge}]$ $+[\mathrm{Sn}])$ ratio in the CZTGeSe compound formed.

$$
\begin{aligned}
& \mathrm{Cu}_{2} \mathrm{ZnSnSe}_{4}+x \mathrm{GeSe}+\frac{x}{2} \mathrm{Se}_{2}(\mathrm{~g}) \\
& \stackrel{475 \pm 10^{\circ} \mathrm{C}}{\longrightarrow} \mathrm{Cu}_{2} \mathrm{Zn}\left(\mathrm{Sn}_{1-x}, \mathrm{Ge}_{x}\right) \mathrm{Se}_{4}+x \mathrm{SnSe}_{2}
\end{aligned}
$$

The reaction is adjusted under the assumption that the number of moles of GeSe incorporated to the CZT $(\mathrm{Ge})$ Se phase is equal to the number of moles of $\mathrm{SnSe}_{2}$ segregated. If the sample is annealed at a high temperature, loss of $\mathrm{SnSe}_{2}$ with time can be observed, resulting in the formation of voids (Figure $5 \mathrm{c}$ ). The segregation of $\mathrm{SnSe}_{2}$ could possibly be avoided by reducing the amount of $S n$ deposited in the precursor. This could also have the implication that the CZTSe phase formed at around $380{ }^{\circ} \mathrm{C}$ grows in a $\mathrm{Cu}$-rich regime, since the $\mathrm{Cu} / \mathrm{Sn}$ ratio would be increased. The consequences of growing the absorber in a $\mathrm{Cu}$ rich regime are still unclear and require further studies.

EDX and SEM analysis suggests that eq 3 takes place near the back contact, where the segregation of the textured $\mathrm{SnSe}_{2}$ occurs and where the Ge accumulation is observed. A key question for the understanding of the formation of the Ge gradient is how the Ge moves from the surface of the original precursor to the back of the film. The real-time measurements showed that the first selenide that forms is $\mathrm{Cu}-\mathrm{Se}$, followed by Ge-poor CZTSe (possibly also $\mathrm{ZnSe}$ or $\mathrm{Cu}_{2} \mathrm{SnSe}_{3}$ ). Only then, the Ge reacts with $\mathrm{Se}$ to form $\mathrm{GeSe}$. We conclude that the formations of $\mathrm{Cu}-\mathrm{Se}$ and CZTSe are enabled by the up-diffusion of $\mathrm{Cu}$ and subsequently $\mathrm{Zn}$ and $\mathrm{Sn}$ toward the surface to react with Se from the gas phase, which has been also observed for the selenization of CZTS nanoparticles. ${ }^{30}$ This means that $\mathrm{Cu}, \mathrm{Zn}$, and $\mathrm{Sn}$ diffuse through the Ge layer which leads to an effective downward movement of Ge. If instead we would assume that Se diffuses into the film to form $\mathrm{Cu}-\mathrm{Se}$ and CZTSe while Ge stays at the surface, the formation of $\mathrm{Ge}-\mathrm{Se}$ would be expected as the first reaction. However, the real-time measurements show that GeSe forms in a later stage. This reaction is similar to the selenization of metallic $\mathrm{Cu}-\mathrm{In}-\mathrm{Ga}$ precursors, where first $\mathrm{Cu}$ and $\mathrm{In}$ react with $\mathrm{Se}$ to form $\mathrm{Cu}-\mathrm{Se}$, In-Se, and finally $\mathrm{CuInSe}_{2}$ on top of the remaining $\mathrm{Ga}$, leading to accumulation of $\mathrm{Ga}$ at the back of the film. ${ }^{31}$

At the boundaries where eq 3 takes place, the CZTGeSe domains have a higher $\mathrm{Ge} /(\mathrm{Ge}+\mathrm{Sn})$ ratio than at the surface of the film (Figure 4). After the reaction occurs, the Ge atoms can diffuse in the $\operatorname{CZT}(\mathrm{Ge})$ Se grains, increasing the $[\mathrm{Ge}] /([\mathrm{Ge}]+$ $[\mathrm{Sn}])$ ratio toward the surface. According to the evaluation of the evolution of the $112 \mathrm{CZT}(\mathrm{Ge})$ Se peak width (Figure 2e), the $\mathrm{Sn}-\mathrm{Ge}$ interdiffusion occurs for around $10 \mathrm{~min}$ until the decrease of the peak width saturates. This finding indicates that the final compositional profile has been reached.

3.4. Implications for Kesterite Solar Cells and Recommendations for Synthesis and Characterization. The results presented in the previous sections clearly demonstrate that during selenization a $\mathrm{Sn}-\mathrm{Ge}$ gradient with increasing $\mathrm{Ge}$ concentration toward the backside of the film forms, even though the Ge was deposited on the precursor surface. The beneficial effects observed in some Ge-incorporated kesterite absorbers in the literature might also be related to this effect. Bearing this in mind, we suggest that future research should strongly consider the phenomenon of $\mathrm{Sn}-\mathrm{Ge}$ compositional gradients, and careful characterization of elemental depth profiles is highly encouraged to support the interpretation of the optoelectronic properties of the samples.

The influence of the Ge-to-Sn ratio on the optoelectronic properties of the sample selenized with one step and $10 \mathrm{~min}$ at $500{ }^{\circ} \mathrm{C}$ was evaluated with $\mathrm{CL}$ at room temperature at the cross section of the film. The evolution of the CL spectra as a function of depth of the absorber layer is depicted in Figure 6a. The intensity of the CL signal is represented in the inset of the figure overlaid with the SEM image as green. No CL signal could be detected in the region with increased Ge concentration and where the segregation of $\mathrm{SnSe}_{2}$ occurs. We speculate that the decrease in luminescence in this region could be due to several factors, for example, (1) decrease in carrier concentration in this region, which has been observed in the literature in Ge-rich kesterites $^{18}$ and thus affects the luminescence yield; ${ }^{43}$ and (2) carrier losses due to the presence of $\mathrm{SnSe}_{2}$ in this region, shown 
to be detrimental for the performance of kesterite solar cells. ${ }^{44} \mathrm{~A}$ red-shift of the maxima of the CL spectra can be observed as the signal originates from the middle of the film $(1 \mu \mathrm{m})$ toward the top surface of the film. This demonstrates the influence of the compositional gradient on the optoelectronic properties of the absorber layer (Figure $6 \mathrm{~b}$ ). For visual comparison, the band-gap $\left(E_{\mathrm{g}}\right)$ values calculated from the EDX signals scaled to an average value of $[\mathrm{Ge}] /([\mathrm{Ge}]+[\mathrm{Sn}])=0.11$ as measured by XRF in an absorber layer processed with an identical precursor are also shown in Figure $6 b^{18}$ The XRF measurement is also in good agreement with the average composition calculated from the EDXRD data (see the Supporting Information, Figure S3). For the $E_{\mathrm{g}}$ calculation from the composition, a band gap of $1.0 \mathrm{eV}$ is assumed for $\mathrm{Cu}_{2} \mathrm{ZnSnSe}_{4}$ and $1.4 \mathrm{eV}$ for $\mathrm{Cu}_{2} \mathrm{ZnGeSe}_{4}$ with a linear increase with Ge content ${ }^{9}$ and error bars with an amplitude of $40 \mathrm{meV}$ to account for variations of band gap with $\mathrm{Cu}$ concentration. ${ }^{45}$ The figure shows that within the error bars the gradient of the CL peak position corresponds to the $E_{\mathrm{g}}$ gradient derived from the Ge and Sn distributions.

This work demonstrates that absorber layers with increased $\mathrm{Ge}$ concentration toward the back contact are obtained even if $\mathrm{Ge}$ is deposited at the top of the precursor layers without the need of a preliminary design of the elemental distribution as attempted by other groups. ${ }^{25}$ By analogy with the knowledge developed for $\mathrm{Ga}$-In dynamics in CIGSe, it can be expected that, in addition to increasing the temperature and annealing time, the use of Secontaining precursors might help promote the $\mathrm{Sn}-\mathrm{Ge}$ interdiffusion. ${ }^{46}$ Future research should focus on how to manipulate the $\mathrm{Sn}-\mathrm{Ge}$ gradient to optimize the optoelectronic properties of the absorber layer.

\section{CONCLUSION}

We studied the formation mechanism of CZT(Ge)Se absorber layers through selenization of metallic precursors via in situ EDXRD/XRF and propose a reaction mechanism that explains the incorporation of $\mathrm{Ge}$ and segregation of $\mathrm{SnSe}_{2}$. The incorporation of Ge occurs after an initial formation of CZTSe. CZTSe reacts with GeSe to form CZTGeSe and $\mathrm{SnSe}_{2}$ at around $475{ }^{\circ} \mathrm{C}$. Our results show that the reaction occurs near the back contact, inducing compositional $\mathrm{Sn}-\mathrm{Ge}$ gradients in the film. The influence of the gradient on the optoelectronic properties has been evaluated with CL showing a gradual red-shift of the emission toward the surface of the film as the Ge content decreases. These compositional gradients could be used for back contact interface passivation and to reduce recombination mechanisms in kesterite absorber layers.

\section{ASSOCIATED CONTENT}

\section{S Supporting Information}

The Supporting Information is available free of charge on the ACS Publications website at DOI: 10.1021/acs.chemmater.7b03416.

Additional temperature and EDXRD/XRF data recorded during different selenizations and a modification of Figure 6b (PDF)

\section{AUTHOR INFORMATION}

\section{Corresponding Author}

*E-mail: jose.marquez_prieto@helmholtz-berlin.de. Phone: +49 30806242235 .

ORCID $\odot$

José Márquez: 0000-0002-8173-2566
Charles J. Hages: 0000-0003-4054-1218

Sergio Giraldo: 0000-0003-4881-5041

Notes

The authors declare no competing financial interest.

\section{ACKNOWLEDGMENTS}

This research was supported by the $\mathrm{H} 2020$ programme under the project STARCELL (H2020-NMBP-03-2016-720907), by MINECO (Ministerio de Economía y Competitividad de España) under the NASCENT project (ENE2014-56237-C41-R), by European Regional Development Funds (ERDF, FEDER Programa Competitivitat de Catalunya 2007-2013) and CERCA Programme/Generalitat de Catalunya. Authors from IREC belong to the M-2E (Electronic Materials for Energy) Consolidated Research Group and the XaRMAE Network of Excellence on Materials for Energy of the "Generalitat de Catalunya”. S.G. thanks the Government of Spain for the FPI fellowship (BES-2014-068533). N.S., H.S., S.L., and D.A. acknowledge the financial support by the Helmholtz Virtual Institute Microstructure Control for Thin-Film Solar Cells (VHVI-520). A.R. thanks the Fonds national de la recherche project for funding within the framework of the projects Nr. 7842175 and Attract project, "Sunspot".

\section{REFERENCES}

(1) Chirilă, A.; Reinhard, P.; Pianezzi, F.; Bloesch, P.; Uhl, A. R.; Fella, C.; Kranz, L.; Keller, D.; Gretener, C.; Hagendorfer, H.; Jaeger, D.; Erni, R.; Nishiwaki, S.; Buecheler, S.; Tiwari, A. N. Potassium-Induced Surface Modification of $\mathrm{Cu}(\mathrm{In}, \mathrm{Ga}) \mathrm{Se}_{2}$ Thin Films for High-Efficiency Solar Cells. Nat. Mater. 2013, 12, 1107-1111.

(2) Jackson, P.; Hariskos, D.; Wuerz, R.; Kiowski, O.; Bauer, A.; Friedlmeier, T. M.; Powalla, M. Properties of $\mathrm{Cu}(\mathrm{In}, \mathrm{Ga}) \mathrm{Se}_{2}$ Solar Cells with New Record Efficiencies up to 21.7\%. Phys. Status Solidi RRL 2015, 9, 28-31.

(3) Jackson, P.; Wuerz, R.; Hariskos, D.; Lotter, E.; Witte, W.; Powalla, M. Effects of Heavy Alkali Elements in $\mathrm{Cu}(\mathrm{In}, \mathrm{Ga}) \mathrm{Se}_{2}$ Solar Cells with Efficiencies up to 22.6\%. Phys. Status Solidi RRL 2016, 10, 583-586.

(4) Witte, W.; Abou-Ras, D.; Albe, K.; Bauer, G. H.; Bertram, F.; Boit, C.; Brüggemann, R.; Christen, J.; Dietrich, J.; Eicke, A.; Hariskos, D.; Maiberg, M.; Mainz, R.; Meessen, M.; Müller, M.; Neumann, O.; Orgis, T.; Paetel, S.; Pohl, J.; Rodriguez-Alvarez, H.; Scheer, R.; Schock, H.-W.; Unold, T.; Weber, A.; Powalla, M. Gallium Gradients in $\mathrm{Cu}(\mathrm{In}, \mathrm{Ga}) \mathrm{Se}_{2}$ Thin-Film Solar Cells. Prog. Photovoltaics 2015, 23, 717-733.

(5) Klinkert, T.; Jubault, M.; Donsanti, F.; Lincot, D.; Guillemoles, J.-F. $\mathrm{Ga}$ Gradients in $\mathrm{Cu}(\mathrm{In}, \mathrm{Ga}) \mathrm{Se}_{2}$ : Formation, Characterization, and Consequences. J. Renewable Sustainable Energy 2014, 6, 11403.

(6) Wang, W.; Winkler, M. T.; Gunawan, O.; Gokmen, T.; Todorov, T. K.; Zhu, Y.; Mitzi, D. B. Device Characteristics of CZTSSe Thin-Film Solar Cells with 12.6\% Efficiency. Adv. Energy Mater. 2014, 4, 1301465.

(7) Hages, C. J.; Redinger, A.; Levcenko, S.; Hempel, H.; Koeper, M. J.; Agrawal, R.; Greiner, D.; Kaufmann, C. A.; Unold, T. Identifying the Real Minority Carrier Lifetime in Nonideal Semiconductors: A Case Study of Kesterite Materials. Adv. Energy Mater. 2017, 7, 1700167.

(8) Persson, C. Electronic and Optical Properties of $\mathrm{Cu}_{2} \mathrm{ZnSnS}_{4}$ and $\mathrm{Cu}_{2} \mathrm{ZnSnSe}_{4}$. J. Appl. Phys. 2010, 107, 53710 .

(9) Chen, D.; Ravindra, N. M. Electronic and Optical Properties of $\mathrm{Cu}_{2} \mathrm{ZnGeX}_{4}(\mathrm{X}=\mathrm{S}$, Se and $\mathrm{Te})$ Quaternary Semiconductors. J. Alloys Compd. 2013, 579, 468-472.

(10) Grossberg, M.; Timmo, K.; Raadik, T.; Kärber, E.; Mikli, V.; Krustok, J. Study of Structural and Optoelectronic Properties of $\mathrm{Cu}_{2} \mathrm{Zn}\left(\mathrm{Sn}_{1-\mathrm{X}} \mathrm{Ge}_{\mathrm{x}}\right) \mathrm{Se}_{4}(\mathrm{x}=0$ to 1$)$ Alloy Compounds. Thin Solid Films 2015, 582, 176-179.

(11) Guc, M.; Levcenko, S.; Izquierdo-Roca, V.; Fontané, X.; Arushanov, E.; Pérez-Rodríguez, A. Polarized Raman Scattering Analysis of $\mathrm{Cu}_{2} \mathrm{ZnSnSe}_{4}$ and $\mathrm{Cu}_{2} \mathrm{ZnGeSe}_{4}$ Single Crystals. J. Appl. Phys. 2013, 114, 193514. 
(12) Garcia-Llamas, E.; Guc, M.; Bodnar, I. V.; Fontané, X.; Caballero, R.; Merino, J. M.; León, M.; Izquierdo-Roca, V. Multiwavelength Excitation Raman Scattering of $\mathrm{Cu}_{2} \mathrm{ZnSn}_{1-\mathrm{x}} \mathrm{Ge}_{\mathrm{x}}(\mathrm{S}, \mathrm{Se})_{4}$ Single Crystals for Earth Abundant Photovoltaic Applications. J. Alloys Compd. 2017, $692,249-256$

(13) Hages, C. J.; Levcenco, S.; Miskin, C. K.; Alsmeier, J. H.; AbouRas, D.; Wilks, R. G.; Bär, M.; Unold, T.; Agrawal, R. Improved Performance of Ge-Alloyed CZTGeSSe Thin-Film Solar Cells through Control of Elemental Losses. Prog. Photovoltaics 2015, 23, 376-384.

(14) Shu, Q.; Yang, J.-H.; Chen, S.; Huang, B.; Xiang, H.; Gong, X.-G.; Wei, S.-H. $\mathrm{Cu}_{2} \mathrm{Zn}(\mathrm{Sn}, \mathrm{Ge}) \mathrm{Se}_{4}$ and $\mathrm{Cu}_{2} \mathrm{Zn}(\mathrm{Sn}, \mathrm{Si}) \mathrm{Se}{ }_{4}$ Alloys as Photovoltaic Materials: Structural and Electronic Properties. Phys. Rev. B: Condens. Matter Mater. Phys. 2013, 87, 115208.

(15) Ross, N.; Larsen, J.; Grini, S.; Vines, L.; Platzer-Björkman, C. Practical Limitations to Selenium Annealing of Compound CoSputtered $\mathrm{Cu}_{2} \mathrm{ZnSnS}_{4}$ as a Route to Achieving Sulfur-Selenium Graded Solar Cell Absorbers. Thin Solid Films 2017, 623, 110-115.

(16) Hwang, D. K.; Ko, B. S.; Jeon, D. H.; Kang, J. K.; Sung, S. J.; Yang, K. J.; Nam, D.; Cho, S.; Cheong, H.; Kim, D. H. Single-Step SulfoSelenization Method for Achieving Low Open Circuit Voltage Deficit with Band Gap Front-Graded $\mathrm{Cu}_{2} \mathrm{ZnSn}(\mathrm{S}, \mathrm{Se})_{4}$ Thin Films. Sol. Energy Mater. Sol. Cells 2017, 161, 162-169.

(17) Yang, K.-J.; Son, D.-H.; Sung, S.-J.; Sim, J.-H.; Kim, Y.-I.; Park, S.N.; Jeon, D.-H.; Kim, J.; Hwang, D.-K.; Jeon, C.-W.; Nam, D.; Cheong, H.; Kang, J.-K.; Kim, D.-H. A Band-Gap-Graded CZTSSe Solar Cell with 12.3\% Efficiency. J. Mater. Chem. A 2016, 4, 10151-10158.

(18) Neuschitzer, M.; Marquez, J.; Giraldo, S.; Dimitrievska, M.; Placidi, M.; Forbes, I.; Izquierdo-Roca, V.; Pérez-Rodriguez, A.; Saucedo, E. Voc Boosting and Grain Growth Enhancing Ge-Doping Strategy for $\mathrm{Cu}_{2} \mathrm{ZnSnSe}_{4}$ Photovoltaic Absorbers. J. Phys. Chem. C 2016, 120, 9661-9670.

(19) Giraldo, S.; Neuschitzer, M.; Thersleff, T.; Lõpez-Marino, S.; Sánchez, Y.; Xie, H.; Colina, M.; Placidi, M.; Pistor, P.; Izquierdo-Roca, V.; Leifer, K.; Pérez-Rodríguez, A.; Saucedo, E. Large Efficiency Improvement in $\mathrm{Cu}_{2} \mathrm{ZnSnSe}_{4}$ Solar Cells by Introducing a Superficial Ge Nanolayer. Adv. Energy Mater. 2015, 5, 1501070-1-1501070-6.

(20) Bag, S.; Gunawan, O.; Gokmen, T.; Zhu, Y.; Mitzi, D. B. Hydrazine-Processed Ge-Substituted CZTSe Solar Cells. Chem. Mater. 2012, 24, 4588-4593.

(21) Collord, A. D.; Hillhouse, H. W. Germanium Alloyed Kesterite Solar Cells with Low Voltage Deficits. Chem. Mater. 2016, 28, 20672073.

(22) Kim, S.; Kim, K. M.; Tampo, H.; Shibata, H.; Matsubara, K.; Niki, S. Ge-Incorporated $\mathrm{Cu}_{2} \mathrm{ZnSnSe}_{4}$ Thin-Film Solar Cells with Efficiency Greater than 10\%. Sol. Energy Mater. Sol. Cells 2016, 144, 488-492.

(23) Kim, S.; Kim, K. M.; Tampo, H.; Shibata, H.; Niki, S. Improvement of Voltage Deficit of Ge-Incorporated Kesterite Solar Cell with 12.3\% Conversion Efficiency. Appl. Phys. Express 2016, 9, 102301.

(24) Hages, C. J.; Carter, N. J.; Agrawal, R.; Unold, T. Generalized Current-Voltage Analysis and Efficiency Limitations in Non-Ideal Solar Cells: Case of $\mathrm{Cu}_{2} \mathrm{ZnSn}\left(\mathrm{S}_{\mathrm{x}} \mathrm{Se}_{1-\mathrm{x}}\right)_{4}$ and $\mathrm{Cu}_{2} \mathrm{Zn}\left(\mathrm{SnyGe}_{1-\mathrm{y}}\right)\left(\mathrm{S}_{\mathrm{x}} \mathrm{Se}_{1-\mathrm{x}}\right)_{4}$. J. Appl. Phys. 2014, 115, 234504.

(25) Kim, I.; Kim, K.; Oh, Y.; Woo, K.; Cao, G.; Jeong, S.; Moon, J. Bandgap-Graded $\mathrm{Cu}_{2} \mathrm{Zn}\left(\mathrm{Sn}_{1-\mathrm{X}} \mathrm{Ge}_{\mathrm{X}}\right) \mathrm{S}_{4}$ Thin-Film Solar Cells Derived from Metal Chalcogenide Complex Ligand Capped Nanocrystals. Chem. Mater. 2014, 26, 3957-3965.

(26) Rodriguez-Alvarez, H.; Kötschau, I. M.; Schock, H. W. PressureDependent Real-Time Investigations on the Rapid Thermal Sulfurization of Cu-In Thin Films. J. Cryst. Growth 2008, 310, 3638-3644.

(27) Genzel, C.; Denks, I. A.; Gibmeier, J.; Klaus, M.; Wagener, G. The Materials Science Synchrotron Beamline EDDI for Energy-Dispersive Diffraction Analysis. Nucl. Instrum. Methods Phys. Res., Sect. A 2007, 578, 23-33.

(28) Fürtauer, S.; Li, D.; Cupid, D.; Flandorfer, H. The $\mathrm{Cu}-\mathrm{Sn}$ Phase Diagram, Part I: New Experimental Results. Intermetallics 2013, 34, 142-147.

(29) Stølen, S.; Fjellvåg, H.; Grønvold, F.; Sipowska, J. T.; Westrum, E. F., Jr. Heat Capacity, Structural and Thermodynamic Properties of
Synthetic Klockmannite CuSe at Temperatures from 5 to $652.7 \mathrm{~K}$ Enthalpy of Decomposition. J. Chem. Thermodyn. 1996, 28, 753-766.

(30) Mainz, R.; Walker, B. C.; Schmidt, S. S.; Zander, O.; Weber, A.; Rodriguez-Alvarez, H.; Just, J.; Klaus, M.; Agrawal, R.; Unold, T. RealTime Observation of $\mathrm{Cu}_{2} \mathrm{ZnSn}(\mathrm{S}, \mathrm{Se})_{4}$ Solar Cell Absorber Layer Formation from Nanoparticle Precursors. Phys. Chem. Chem. Phys. 2013, $15,18281$.

(31) Mainz, R.; Weber, A.; Rodriguez-Alvarez, H.; Levcenko, S.; Klaus, M.; Pistor, P.; Klenk, R.; Schock, H. W. Time-Resolved Investigation of $\mathrm{Cu}(\mathrm{In}, \mathrm{Ga}) \mathrm{Se}_{2}$ Growth and $\mathrm{Ga}$ Gradient Formation during Fast Selenisation of Metallic Precursors. Prog. Photovoltaics 2015, 23, $1131-1143$.

(32) Olekseyuk, I. D.; Dudchak, I. V.; Piskach, L. V. Phase Equilibria in the $\mathrm{Cu}_{2} \mathrm{~S}-\mathrm{ZnS}-\mathrm{SnS}_{2}$ System. J. Alloys Compd. 2004, 368, 135-143.

(33) Weber, A.; Mainz, R.; Schock, H. W. On the Sn Loss from Thin Films of the Material System Cu-Zn-Sn-S in High Vacuum. J. Appl. Phys. 2010, 107, 13516.

(34) Redinger, A.; Berg, D. M.; Dale, P. J.; Siebentritt, S. The Consequences of Kesterite Equilibria for Efficient Solar Cells. J. Am. Chem. Soc. 2011, 133, 3320-3323.

(35) Scragg, J. J.; Dale, P. J.; Colombara, D.; Peter, L. M. Thermodynamic Aspects of the Synthesis of Thin-Film Materials for Solar Cells. ChemPhysChem 2012, 13, 3035-3046.

(36) Marquez-Prieto, J.; Pearsall, N. M.; Forbes, I. Growth of A-Type CZTSe Absorber Layers via the Controlled Formation and Loss of $\mathrm{SnSe}_{2}$ during the Selenisation Step. In Photovoltaic Science, Applications and Technology (PVSAT-12) conference; 2016.

(37) Ren, Y.; Ross, N.; Larsen, J. K.; Rudisch, K.; Scragg, J. J. S.; PlatzerBjörkman, C. Evolution of $\mathrm{Cu}_{2} \mathrm{ZnSnS}_{4}$ during Non-Equilibrium Annealing with Quasi-in Situ Monitoring of Sulfur Partial Pressure. Chem. Mater. 2017, 29, 3713-3722.

(38) Wiedemeier, H.; Csillag, F. J. Equilibrium Sublimation and Thermodynamic Properties of SnS. Thermochim. Acta 1979, 34, 257265.

(39) Apel, D.; Klaus, M.; Genzel, C.; Balzar, D. Rietveld Refinement of Energy-Dispersive Synchrotron Measurements. Zeitschrift fur Krist. 2011, 226, 934-943.

(40) Márquez-Prieto, J.; Ren, Y.; Miles, R. W.; Pearsall, N.; Forbes, I. The Influence of Precursor $\mathrm{Cu}$ Content and Two-Stage Processing Conditions on the Microstructure of $\mathrm{Cu}_{2} \mathrm{ZnSnSe}_{4}$. Thin Solid Films 2015, 582, 220-223.

(41) Kötschau, I. M.; Schock, H. W. Compositional Depth Profiling of Polycrystalline Thin Films by Grazing-Incidence X-Ray Diffraction. J. Appl. Crystallogr. 2006, 39, 683-696.

(42) Carter, N. J.; Mainz, R.; Walker, B. C.; Hages, C. J.; Just, J.; Klaus, M.; Schmidt, S. S.; Weber, A.; Yang, W.-C. D.; Zander, O.; Stach, E. A.; Unold, T.; Agrawal, R. The Role of Interparticle Heterogeneities in the Selenization Pathway of $\mathrm{Cu}-\mathrm{Zn}-\mathrm{Sn}-\mathrm{S}$ Nanoparticle Thin Films: A Real-Time Study. J. Mater. Chem. C 2015, 3, 7128-7134.

(43) Unold, T.; Gütay, L. Photoluminescence Analysis of Thin-Film Solar Cells. In Advanced Characterization Techniques for Thin Film Solar Cells; Wiley-VCH Verlag GmbH \& Co. KGaA, 2011; pp 151-175.

(44) Temgoua, S.; Bodeux, R.; Naghavi, N.; Delbos, S. Effects of $\mathrm{SnSe}_{2}$ Secondary Phases on the Efficiency of $\mathrm{Cu}_{2} \mathrm{ZnSn}\left(\mathrm{S}_{\mathrm{x}} \mathrm{Se}_{1-\mathrm{x}}\right)_{4}$ Based Solar Cells. Thin Solid Films 2015, 582, 215-219.

(45) Márquez, J.; Neuschitzer, M.; Dimitrievska, M.; Gunder, R.; Haass, S.; Werner, M.; Romanyuk, Y. E.; Schorr, S.; Pearsall, N. M.; Forbes, I. Systematic Compositional Changes and Their Influence on Lattice and Optoelectronic Properties of $\mathrm{Cu}_{2} \mathrm{ZnSnSe}_{4}$ Kesterite Solar Cells. Sol. Energy Mater. Sol. Cells 2016, 144, 579-585.

(46) Moon, D. G.; Yun, J. H.; Gwak, J.; Ahn, S.; Cho, A.; Shin, K.; Yoon, K.; Ahn, S. Cu(In,Ga)Se ${ }_{2}$ Thin Films without Ga Segregation Prepared by the Single-Step Selenization of Sputter Deposited Cu-InGa-Se Precursor Layers. Energy Environ. Sci. 2012, 5, 9914-9921. 